\title{
A nacionalização do ensino em áreas de colonização italiana: o caso da Escola Garibaldi e da Colônia Maciel (1937-1945)
}

\author{
Renata Brião de Castro* \\ Patrícia Weiduschadt ${ }^{* *}$
}

\begin{abstract}
Resumo
Este artigo tem como objetivo analisar a Escola Garibaldi e a Colônia Maciel em Pelotas (RS) durante o período da nacionalização do ensino (1937- 1945). Será discutido como repercutiu entre os imigrantes de origem italiana as medidas referentes à política de Nacionalização do Ensino na escola e na localidade. Serão utilizadas, como fontes de pesquisa, dois periódicos do município, relatórios do Município de Pelotas, fontes orais constituídas como acervo em uma instituição museológica, entrevistas realizadas pelas pesquisadoras, além de imagens. Ao analisar o corpus empírico nota-se que a nacionalização foi sentida na localidade e na escola.

Palavras-chave: História da Educação; educação rural; Pelotas; Nacionalização do ensino.
\end{abstract}

\section{The nationalisation of education within Italian settlement areas: the case of Garibaldi School and Maciel Colony (1937-1945).}

\begin{abstract}
This article aims to analyze the Garibaldi School and the Maciel Colony in Pelotas (RS) during the period of nationalization of education (1937-1945). It will be discussed how the measures concerning the policy of Nationalization of the school and in the locality reflected among the immigrants of Italian origin. As sources of research, two periodicals of the municipality, reports of the Municipality of Pelotas, oral sources constituted as collection in a museological institution, interviews conducted by the researchers, as well as images will be used as sources of research. When analyzing the empirical corpus we can see that the nationalization was felt in the locality and in the school.

Keywords: History of the Education; rural education; Balls; nationalization of the teaching.
\end{abstract}

\section{Introdução}

Este trabalho tem como objetivo analisar a Escola Garibaldi e a Colônia Maciel (Pelotas/RS) durante o período da nacionalização do ensino (1937-1945). Outrossim, o artigo traz dados e informações acerca de outras localidades e instituições escolares do município de Pelotas. Esteve presente, na região pesquisada, a imigração alemã, desta forma o texto, também, utiliza-se de dados referentes a este grupo étnico. Apesar de o recorte temporal estar estabelecido entre os anos do Estado Novo utilizam-se dados de outros anos para contextualização.

A Escola Garibaldi foi construída no ano de 1928. As aulas iniciaram no ano seguinte sob a regência do professor José Rodeghiero, o qual permaneceu na instituição até o ano de 1950. Durante esses anos, o professor escreveu um manuscrito intitulado "Histórico da Escola Garibaldi", neste descrevem-se alguns acontecimentos da instituição escolar e do andamento das atividades docentes.

O presente texto é um recorte da dissertação

* Endereço eletrônico: renatab.castro@gmail.com

*** Endereço eletrônico: prweidus@ gmail.com de mestrado, a qual teve como objetivo analisar a Escola Garibaldi no recorte temporal de 1928 a 1950, dando ênfase na figura do professor José Rodeghiero. Deste modo, dentro dessa periodização há as políticas nacionalizadores do Estado Novo. Assim, foi necessário entender como se deram as medidas referentes à nacionalização na localidade, bem como na instituição escolar analisada. É oportuno ressaltar que a escola analisada, Escola Garibaldi, esteve desde o seu início dentro da esfera pública municipal. $\mathrm{O}$ artigo utiliza-se de fontes escritas e orais, tais como: os relatórios da Intendência Municipal de Pelotas, dois periódicos "Diário Popular" e "A Opinião Pública" -, entrevistas constituídas como acervo em uma instituição museológica (Museu Etnográfico da Colônia Maciel - MECOM), além de entrevistas realizadas pelas pesquisadoras.

Sobre o recorte espacial, o estudo está inserido em uma área geográfica que passou pelo processo de imigração europeia no século XIX, por isso as políticas de nacionalização do ensino tiveram repercussões. A Serra dos Tapes inclui em sua faixa territorial as áreas dos atuais municípios 
de Pelotas, Morro Redondo, Capão do Leão, Arroio do Padre, Turuçu, Canguçu e São Lourenço do Sul (CERQUEIRA et al., 2010, p.876). As terras dessa serra foram destinadas aos núcleos coloniais imigratórios no século XIX, por não serem apropriadas a exploração pecuária.

Assim sendo, no tópico subsequente será abordado em um primeiro momento, o contexto da época, bem como a nacionalização para grupos imigrantes. De forma geral, discute-se sobre a restrição da língua italiana falada na região, as notícias encontradas nos periódicos locais referentes à nacionalização do ensino, a resistência da comunidade a outras pessoas que não as do local, alguns indicativos de que a comunidade teve certa dificuldade em se adaptar, tendo em vista a vontade de manutenção de alguns de seus costumes. Analisam-se, outrossim, algumas imagens, nas quais notam-se elementos indicadores de que a nacionalização do ensino estava presente na escola e na região.

\section{As fontes da pesquisa: entrelaçamento entre teoria e empiria}

Como o trabalho faz uso de entrevistas, sob a metodologia da história oral, são necessárias algumas reflexões sobre o campo da memória, uma vez que não há como dissociá-las. A memória é "guardada" em diferentes suportes, há os lugares de memória (NORA, 1993) representados pelas fotos, pela materialidade do cotidiano escolar, assim como a memória que é suscitada pelas narrativas. É preciso compreender que a memória é seletiva. Assim sendo, torna-se imprescindível reforçar que não se está a reproduzir os fatos tais quais eles aconteceram, mas, sim, a reinterpretá-los. Quando se utiliza a memória dos sujeitos, seja ela realizada pelos pesquisadores ou armazenada em acervos, esta não é uma reconstituição do passado, tal como aconteceu. O que é rememorado são os acontecimentos e vivências guardadas pelos narradores. Se, por um lado, não é possível lembrar de tudo, pois a lembrança se vale de estratégias para lembrar o que lhe é significativo e esquecer acontecimentos não marcantes, por outro lado, ao evocar estas lembranças, o narrador pode não falar sobre determinados pontos ou assuntos que não lhe sejam confortáveis. Nessa linha: “[...] a lembrança é em larga medida uma reconstrução do passado com a ajuda de dados emprestados do presente, onde a imagem de outrora se manifestou já bem alterada" (HALBWACHS, 2004, p. 76). Assim, na análise das memórias, a partir das narrativas orais, é necessário ter em mente de que ao evocar suas lembranças, os narradores falam no presente. Os sujeitos entrevistados relembram, também, de acordo com a memória coletiva de determinado grupo, conforme Halbwachs:

Cada grupo definido localmente tem sua própria memória e uma representação do tempo que é somente dele. Acontece que cidades, províncias, povos, fundem-se numa nova unidade, logo o tempo comum se amplia e, talvez, avance mais no passado, ao menos para uma parte do grupo, que se encontra então a participar de tradições mais antigas (HALBWACHS, 2004, p. 111).

Para o autor, o indivíduo lembra a partir de referências coletivas. $\mathrm{O}$ grupo, dentro do qual esse sujeito que recorda está incluído, influencia na consolidação das memórias. Halbwachs (2004) explica a necessidade de as memórias dos narradores terem um ponto de contato entre si. Para fazer sentido é necessário, em algum momento, as narrativas cruzarem-se. Nesse contexto, considerando as fontes empíricas do presente estudo, observa-se, em muitas das narrativas, a recorrência do tema da nacionalização. Com frequência os entrevistados rememoraram, por exemplo, a proibição de falar o italiano na região e na escola.

Como se mencionou, considera-se, neste texto, a história oral como uma metodologia. Há vertentes e autores que a tratam como técnica ou ainda como disciplina, conforme Ferreira e Amado (2006, p. XVI):

[...] como todas as metodologias, apenas estabelece e ordena procedimentos de trabalho tais como os diversos tipos de entrevista e as implicações de cada um deles para a pesquisa, as várias possibilidades de transcrição de depoimentos, suas vantagens e desvantagens, as diferentes maneiras do historiador relacionar-se com seus entrevistados e as influencias disso sobre seu trabalho -, funcionando como ponte entre teoria e prática. Esse é o terreno da História oral - o que a nosso ver não permite classificá-la unicamente como prática.

Quanto aos tipos de história oral, utiliza-se a chamada história oral temática, ao compreender que não se está fazendo uma biografia ou história de vida, mas dentro de um tema, analisam-se as questões da pesquisa. A história oral temática dispõe a discussão ao redor de um tema central, 
podendo decorrer outros no processo. Recomendase que o pesquisador, neste tipo de abordagem, esteja preparado previamente sobre o assunto a ser tratado. Outrossim, a escolha dos sujeitos entrevistados faz-se fundamental nessa etapa, (MEIHY; HOLANDA, 2014). Para Weiduschadt e Fischer (2009), a história oral temática especifica-se por produzir narrativas em torno de um acontecimento, de um tema estabelecido dentro de um período de tempo.

Por serem utilizadas neste artigo entrevistas que são acervo é necessário fazer essa distinção, trabalha-se com dois grupos de entrevistas. Um que foi realizado pelas pesquisadoras e outro que já estava constituído e não teve como objetivo esta pesquisa. Almeida e Grazziotin (2016) reforçam que: "para garimpar as informações necessárias aos pesquisadores que farão uso do acervo é necessário perambular pelas transcrições, construir categorias e regimes de inteligibilidades que confiram coerência à narrativa histórica e possibilitem sua compreensão em determinado espaço e tempo" (ALMEIDA, GRAZZIOTIN, 2016, p. 1038). Dessa forma, com o acervo oral foi necessário primeiramente uma organização das informações disponíveis, para depois analisar de forma aprofundada as narrativas ${ }^{1}$.

Os dois periódicos utilizados, Diário Popular e A Opinião Pública, podem ser caracterizados quanto ao número de páginas das edições diárias dos jornais, estas oscilam de 06 a 12 páginas diárias dependendo do ano. Algo perceptível nos dois periódicos é o aumento do número de páginas conforme os anos vão-se aproximando da atualidade. A escolha dos periódicos, Diário Popular e A Opinião Pública, durante os anos de 1928 a 1950 deve-se ao fato de serem os dois que abrangiam todo o recorte temporal, além de serem os principais periódicos circulados no município neste período. Oliveira (2005) traz, em sua dissertação, uma descrição desses periódicos. O jornal Diário Popular era o órgão oficial do Partido Republicano RioGrandense $\left(\mathrm{PRR}^{2}\right)$, foi fundado no ano de 1890 como um órgão oficial do PRR até o final da República Velha. Já o jornal A Opinião Pública denominava-se um órgão de interesses gerais. Entretanto, conforme Oliveira (2005), mantinha vínculos com o PRR. Esse periódico começou a circular em 1896 e sua fundação deve-se a uma dissidência partidária dentro do Diário Popular. A equipe original deste abandonou o jornal e fundou A Opinião Pública (LONER, 1998 apud OLIVEIRA, 2005). O uso de jornais como fonte de pesquisa ampara-se em Tania de Luca (2015). Para a autora, a importância dos periódicos está amplamente aceita, segue Luca $(2015$, p. 130), e "[...] o seu uso generalizou-se a ponto de se tornar um dos traços distintivos da produção acadêmica brasileira a partir de 1985". Zicman (1985) pontua que a apresentação das notícias na imprensa impressa não é uma repetição de acontecimentos e cada jornal organiza as informações que irão ser veiculadas segundo seu próprio filtro.

Outro aspecto ressaltado por Luca (2015) refere-se à materialidade dos jornais e sua periodicidade. Os periódicos consultados - Diário Popular e A Opinião Pública - estão todos disponíveis para consulta na hemeroteca da Bibliotheca Pública Pelotense, alguns anos encadernados por semestre e outros por quadrimestres. Neste sentido, a pesquisa foi facilitada pelo fato de estarem todos os jornais salvaguardados na mesma instituição de memória. Após findada a etapa de folhear os periódicos, foi necessário organizar e categorizar os dados. Para Zicman (1985), o processo de categorização dos dados dos periódicos ocorre em dois momentos: primeiro o inventário, os elementos, e depois a classificação, que seria a distribuição destes elementos em grupos análogos. $\mathrm{O}$ autor alerta para a necessidade de o pesquisador definir suas categorias de análise conforme os objetivos de sua pesquisa.

Quanto aos materiais presentes no arquivo da Escola Garibaldi, foram observados os livros de atas de exames finais da instituição escolar, assim como os livros de disciplinas, nestes é possível perceber quais disciplinas foram ministradas ao longo dos anos, bem como possibilitou ver anotações de quem fiscalizava esses documentos. Sobre estes documentos da escrituração escolar Gil e Hawat (2015), escrevem que pensar essa escrita é também refletir sobre a prática dos docentes que não se restringe somente a ensinar, mas ao que é registrado pelos professores e dão visibilidades à suas atividades e servem para apoiar a memória. Esses registros são suportes de memória de determinada instituição escolar e permitem conhecer os sujeitos da escola. Para Gil e Hawat (2015), os livros de matrícula, mapas de frequência, atas de exames, diários de classes, livro ponto de professores, entre outros materiais são suportes da escrita escolar, os quais têm entre os propósitos fiscalizar e organizar as práticas escolares.

Sobre o uso de imagens como fonte para a pesquisa Mauad e Lopes (2014, p. 283), escrevem que: "as imagens são ricas e, por vezes, podem 
parecer comunicar mais do que se quer mostrar". Seguem os autores:

As imagens despertam julgamentos estéticos e críticas filosóficas, sempre articulados com as culturas dos que as produzem e de seus leitores, seja no processo histórico que caracterizou o tempo de sua criação e circulação, seja no tempo em que elas se tornam fontes e documentos para os estudos dos autores aqui reunidos. Os meios pelos quais elas circulam redefinem seus usos, funções e significados (MAUAD; LOPES, 2014, p. 283).

De acordo com Bencostta (2011), é bastante comum ainda em pesquisas o uso de fotografias meramente ilustrativas. Para o autor, as imagens das instituições escolares constituem-se em testemunho das escolas e revelam também como estas eram concebidas. Para refletir sobre o uso de fotografias em pesquisas históricas busca-se apoio em Burke (2004), "[...] historiadores, da mesma forma que fotógrafos, selecionam que aspectos do mundo real vão retratar" (BURKE, 2004, p. 27). Neste ponto, é possível perceber que a fotografia é uma representação, quem fotografou escolheu uma maneira para isso. Para Mauad (1996, p. 8), "a fotografia é uma fonte histórica que demanda por parte do historiador um novo tipo de crítica. O testemunho é válido, não importando se o registro fotográfico foi feito para documentar um fato ou representar um estilo de vida". Assim como nas outras tipologias de fontes é necessário problematizar esses documentos, entendendo que as imagens representam algo. Assim sendo, compreende-se o potencial do uso de imagens como fonte para pesquisas, uma vez que com a devida análise da problemática e contexto de sua produção é possível fazer algumas inferências quanto aos aspectos das fotografias.

Com exceção das entrevistas que foram realizadas com fins específicos para esta pesquisa, as demais fontes foram produzidas com outras intencionalidades, os documentos da escrituração escolar tiveram como propósito organizar o espaço escolar, bem como cumprir as normativas de registrar a vida escolar. As notícias de jornais são veiculadas com o propósito de informar e, também, dar destaque aquilo que a impressa considerava como importante, pois como já se mencionou as matérias de jornais não são neutras, são uma representação daquilo que o jornal deseja veicular. Cabe assim, ao historiador dar ressignificação a esses materiais, é tarefa dele transformar em documentos para a pesquisa histórica. Michel de Certeau (1982) escreve que um dos primeiros trabalhos dos pesquisadores é organizar os dados e distribuí-los de outra forma. É necessário, ao historiador, o exercício da crítica às fontes, não as tomando como um fiel retrato do passado. Muitos autores (LE GOFF, 1990; CERTEAU, 1982; BURKE, 2005; PESAVENTO, 2004, entre outros) pontuam a tarefa básica de todo historiador: fazer a crítica aos documentos, problematizá-los e questioná-los para que estes possam "falar" algo. Para Le Goff (1990), é necessário ir à direção dos documentos/monumentos. "[...] Só a análise do documento enquanto monumento permite à memória coletiva recuperá-lo e ao historiador usá-lo cientificamente, isto é, com pleno conhecimento de causa" (LE GOFF, 1990, p. 495). Nesse momento, explicita-se a perspectiva teórica utilizada neste trabalho, a História Cultural. Por esse viés, considera a importância de realizar a crítica as fontes e não somente descreve-las. Ainda observarse a relevância do cruzamento dos diversos tipos de fontes de pesquisa, no caso aqui: narrativas orais; notícias de jornais, documentos da escrituração escolar e algumas legislações municipais.

\section{Nacionalização em áreas de imigração}

Em 1930 tem fim o que a historiografia convencionou denominar República Velha ou Primeira República. Tem início, então, o governo de Getúlio Vargas, o qual na história política do país está subdividido em três momentos, governo provisório, constitucional e Estado Novo.

O Estado Novo é instaurado em 1937 através do qual as políticas para a Nacionalização do Ensino foram efetividades. No plano político educacional, nesse período, o Ministério da Educação foi ocupado por Gustavo Capanema, o qual implantou uma série de reformas conhecidas como Leis Orgânicas do Ensino.

Após a posse de Getúlio Vargas foi criado o Ministério da Saúde e Educação Pública. Francisco Campos assumiu a nova pasta e baixou sete decretos, os quais ficaram conhecidos como Reforma Francisco Campos. Fica evidente a preocupação do governo em tratar a educação como uma questão nacional nos diversos níveis (SAVIANI, 2007). Para Xavier (2005), desde o início do governo Vargas, a concepção da educação como um problema foi usada para justificar uma intervenção do Estado, a escola foi um dos meios para a proliferação do nacionalismo. 
Durante o período do Estado Novo a política educacional orientava-se pelos aspectos constituintes desse, ou seja, centralização, autoritarismo, nacionalização e modernização. Desta forma, a política para a educação desenvolveu-se de modo autoritário. Com o propósito de reforçar o nacionalismo nos currículos escolares deu-se importância aos estudos de educação física, ensino da moral católica, educação cívica por meio da história e geografia do Brasil. Foram criados órgãos federais tais como: o Ministério da Saúde e Educação Pública no ano de 1931, o Conselho Nacional de Educação no mesmo ano, a Comissão do Ensino Primário em 1938, o Fundo Nacional do Ensino Primário no ano de 1942, entre outros órgãos (HILSDORF, 2003).

De acordo com Weiduschadt (2009), uma política não consegue ser implementada se não houver uma série de fatores que a legitimam. Conforme a autora, antes de 1930 existiam iniciativas para a implantação dessas políticas nacionalizadoras. Dentro desse ambiente, o Brasil, substancialmente no período do Estado Novo intensifica essas políticas, assim como os mecanismos de controle. Conforme Corsetti et al. (2007), as políticas para a nacionalização do ensino tiveram impacto, sobretudo, nas regiões de colonização italiana e alemã. Sentiram os efeitos dessa lei as escolas étnicas, confessionais, comunitárias ligadas a grupos étnicos, os quais tinham interesse na manutenção de seus costumes e de sua língua ou dialeto. Como mencionado anteriormente, no município de Pelotas (RS) houve imigração de outras etnias, como, por exemplo, a alemã.

Para Weiduschadt (2009), os imigrantes de origem alemã possuíam uma organização escolar para seus filhos, tinham escolas comunitárias étnicas e confessionais e nestas privilegiavam a língua alemã. Havia deste modo, pressão nessas localidades para cultivar a nacionalidade brasileira. Entretanto, conforme a autora, se por um lado, havia a imposição à nacionalização, por outro, não havia, antes da década de 1930, a fiscalização em todas as escolas. Na década de 30, o governo de Getúlio Vargas criou as condições e mecanismos favoráveis para efetivar a nacionalização.

No estado do Rio Grande do Sul o movimento de nacionalização teve fortalecimento, juntamente com a repressão, na figura de Coelho de Souza, Secretário de Educação do Estado (WEIDUSCHADT, 2009). Para Schwartzman et al. (1984), o interventor do Estado do Rio Grande do
Sul, Cordeiro de Farias, cumpriu à risca o programa de fechamento das escolas ligadas aos grupos étnicos, nomeando diretores brasileiros para estas. A Campanha de Nacionalização foi abrangente em todo o país. Contudo, a ação nacionalizadora mostrou-se mais nítida na região sul do Brasil, onde havia zonas de colonização (SCHWARTZMAN, 1984, p. 362).

Para Seyferth (1999), a partir de 1937 foram tomadas medidas coercitivas no sentido de nacionalizar as comunidades étnicas imigrantes. Segundo a mesma autora, no sul do país a colonização produziu colônias de diversas etnias tais como, italiana, alemã, polonesa, ucraniana.

No que tange aos imigrantes italianos, a maior concentração no RS foi na região serrana do estado, mas houve, também, em menor escala, em outras regiões, como, por exemplo, em Pelotas, porém com algumas diferenças significativas em relação à região da serra gaúcha. A principal delas é o município de Pelotas já estar estruturado quando os imigrantes chegaram e isso pode ter influenciado nas questões educacionais. Pelotas não foi um município constituído a partir da imigração, conforme Caxias, Bento Gonçalves e Garibaldi, por exemplo. Os imigrantes vieram para colonizar pontos vazios demograficamente, tais como na região serrana do Estado do RS, entretanto Pelotas já era um município formado.

As medidas de nacionalização fizeram-se sentir não só no espaço da sala de aula, mas também no espaço da comunidade. A proibição de falar línguas estrangeiras extrapolava o ambiente escolar. Além disso, as festividades, por exemplo, da Semana da Pátria envolviam o entorno da escola, numa tentativa de nacionalizar por meio das instituições escolares. Tambara et al. (2007) esclarece que a nacionalização no estado do RS compreendeu duas ordens:

As medidas de nacionalização no estado compreenderam duas ordens de ações: extraescolar e escolar. A ação educativa extraescolar envolvia a realização de caravanas nacionalistas e comemorações das datas cívicas [...]. No âmbito escolar, a ação obedeceu a uma série de medidas que foram orientadas, inicialmente, pela regulamentação das redes de escolas particulares estrangeiras. [...]. Um corpo seleto de fiscais, distribuídos por todos os municípios, passou a vigiar, permanentemente, esses colégios. Eram os inspetores de ensino, que, atuando junto às escolas forneciam ao governo do estado informações indispensáveis à ação nacionalizadora do ensino, tendo como

Horizontes, v. 36, n. 2, p. 19-35, mai./ago. 2018 
alicerce a escola elementar. Também a professora da nacionalização, indicada pelas autoridades educacionais, para atuar junto à escola particular nacionalizada, tinha função de controle e observação da implementação das medidas oficiais (TAMBARA ET AL., 2007, p. 320-321).

Nesse ínterim, há o entendimento de que a nacionalização atingiu tanto o espaço escolar como o social. Conforme os autores acima, é possível, dentro do ambiente escolar, realizar a divisão extraescolar e escolar. Relacionando com os dados empíricos desse estudo, podemos notar que na Escola Garibaldi a nacionalização fazia-se sentir nos dois momentos. Dentro da escola não se falava o idioma italiano, tampouco ministravam-se aulas nesta língua, havia por parte do poder público municipal uma fiscalização mais detalhada dos documentos da escrituração escolar no período do Estado Novo. Ainda, os alunos da escola participavam da caravana dos coloninhos da Capital do Estado, Porto Alegre (RS), conforme será detalhado mais adiante. Para além do espaço da escola, os entrevistados relembram da proibição do uso do italiano nesse período, conforme as memórias, o idioma ficou restrito ao espaço doméstico. Assim, este pode ser considerado um dos motivos para a não manutenção do idioma, atualmente não se fala mais o dialeto do italiano na região.

A partir dos jornais percebem-se discursos acerca da importância e da necessidade de nacionalizar. Posteriormente, encontram-se anúncios de instituições escolares fechadas por descumprirem as normativas. No ano de 1938 há uma notícia abordando esse assunto em todo o Estado do Rio Grande do Sul, conforme a matéria estava sendo redigido um projeto de nacionalização do ensino para as escolas, principalmente as alemãs, italianas, polonesas e israelitas (DIÁRIO POPULAR, 29/03/1938, p. 1). Ao longo de todo esse ano encontram-se reportagens sobre a necessidade e a importância de nacionalizar.

Além do mais, nos relatórios da Intendência Municipal há um discurso acerca da nacionalização do ensino, trazendo, inclusive, exemplos de escolas e professores que desrespeitavam essa normativa. Os relatórios trazem esses dados referentes às escolas que ministrariam o ensino na língua alemã, porém, através destes, consegue-se visualizar como a imprensa noticiava estes acontecimentos.

São veiculadas, também, notícias sobre as comemorações da Semana da Pátria no município de Pelotas e a participação das escolas nessas festividades. No ano de 1940, no programa de festas organizado para comemorar a Semana da Pátria, há uma hora programada para um "grande desfile de todas as escolas particulares, públicas e grupos" (DIÁRIO POPULAR, 01/09/1940, p. 2).

Outra notícia ressalta que todas as escolas rurais irão participar das festividades e alguns alunos das escolas rurais de Pelotas irão participar das comemorações na capital do Estado, Porto Alegre (DIÁRIO POPULAR, 31/08/1939, p. 8).

Luchese (2014) argumenta que entre as comemorações cívicas, no caso do Estado do Rio Grande do Sul, uma das mais importantes iniciativas foram as comemorações da Semana da Pátria na capital do estado com a participação dos "coloninhos". Conforme a autora, esses eram também chamados de "gauchinhos" e eram recebidos, na capital, pelo governador do RS. A autora aborda os imigrantes de origem italiana concentrados na região serrana do estado do RS. Porém, é perceptível através da análise dos periódicos que no município de Pelotas os alunos das escolas rurais participavam dessas festividades. Segue a notícia:

Já se encontram em Pelotas quarenta dos coloninhos que vão a Porto Alegre assistir às festas da Semana da Pátria.

Alunos da zona colonial vão a Porto Alegre para as comemorações da Semana da Pátria. Colégios de Santa Silvana, Morro Redondo, $3^{\circ}$ distrito (DIÁRIO POPULAR, 24/08/1940, p. 8).

Não há detalhamento de quais escolas teriam ido a Porto Alegre para as festividades, entretanto torna-se significativo observar a presença desta notícia no jornal. Dois pontos são importantes, um deles, a ida desses alunos as comemorações em Porto Alegre e, o segundo, o jornal reproduzir essas informações em uma tentativa de mostrar a importância desses eventos. Ao correlacionar com as entrevistas realizadas percebe-se, através das narrativas, que havia na Escola Garibaldi festividades na semana da pátria, realizadas na localidade da Colônia Maciel. Ao realizar entrevistas com os alunos que estudaram na década de 1940 é ressaltado, por eles, que dois alunos da Escola Garibaldi participavam das comemorações da Semana da Pátria. Um dos entrevistados rememora suas viagens:

Numa ocasião, não sei que semana da Pátria foi, ao redor dessa ai, a Secretaria de Educação 
organizou o passeio para os alunos da região colonial, uma semana da pátria, perto dessa ai, não sei se foi antes ou depois [foto], para ir a Porto Alegre, desfilar lá na Borges de Medeiros, iam 30 alunos, dois de cada colégio, eu sei que foi 2 de cada colégio, a gente foi de navio, eu fui, eu e outro colega que estava junto, foi um bom passeio, a gente não conhecia nada, navio cruzeiro que fazia a linha Pelotas a Porto Alegre, tinha camarote e tudo, comida. Saia daqui e era Cruzeiro o nome do navio, [...] mas foi um belo de um passeio (N. R, depoimento agosto de 2016).

Conforme este entrevistado, todos os anos dois alunos iam a Porto Alegre, isto é indicativo das medidas nacionalizadoras na localidade. É interessante notar que o entrevistado evoca como algo positivo para os alunos, não se tem a clareza, na época, de que era uma atividade que fazia parte de uma política maior de nacionalização.

Conforme as narrativas, havia desfiles durante toda a semana na frente da Escola Garibaldi: "naquela época, quando era sete de setembro, eles desfilavam, a gente marchava, agora meio terminou tudo, tem ainda, mas aqui na colônia no colégio, não tem mais isso. Tinha assim, os tambores, os que batiam para marchar, tudo assim. No colégio fazia-se aquele circulatório ali" (O. C. 2015).

Luchese (2014), tratando da Região Colonial Italiana, escreve que a nacionalização atingiu de diversas maneiras os imigrantes italianos. Conforme a autora, o grupo dos italianos foi menos reprimido em relação a outros grupos, entretanto não se pode deixar de notar que as medidas foram sentidas.

Uma das práticas de nacionalização, na região pesquisada pela autora, foi a mudança dos nomes de praças, ruas, escolas, localidades, distritos modificados. As denominações que lembravam a Itália foram substituídas por pessoas e eventos considerados importantes para a história brasileira. Uma das medidas centrais foi a questão linguística e a utilização, a partir de então, do português (LUCHESE, 2014). Dentro dessa conjuntura estava o ensino na língua portuguesa.

Nas entrevistas do banco de dados do Museu Etnográfico da Colônia Maciel - MECOM , essas demostram que durante a $2^{\mathrm{a}}$ Guerra Mundial foi reprimido o idioma italiano, segue abaixo algumas dessas memórias:

Pesquisador (P)3: O senhor começou falando italiano?

Entrevistador (E): É. A minha vida eu comecei só sabendo falar italiano. Depois que eu entrei na escola é que eu aprendi a falar em brasileiro. Mas até a guerra, minha mãe e meu pai deixavam nós falar italiano à vontade. Depois que deu aquela guerra, eu não sei o que houve naquele tempo. Ela não queria que nós falássemos mais italiano em casa. Nós brigávamos, mas não adiantava nada. Nós sempre falávamos, e eles não. O pai e a mãe, ele começou a falar em brasileiro. Se não era só italiano. Só italiano (MECOM 44).

P: Queria perguntar paro senhor, quando é que deixaram de falar italiano?

E: Deixaram? Isso aí foi indo, foi indo, devagarzinho, foi parando, e pararam, né.

$\mathrm{P}$ : Teve alguma coisa a ver com guerra?

E: Era 45 , foi em $45 \ldots 45$ que era meio proibido falar em italiano, depois proibiram os alemães também de falar em alemão. Mas os italianos não foram perseguidos. Mas houve, eles não gostavam muito que o cara falasse o italiano, foi nesta última guerra que brigo Alemanha e Itália tudo junto (MECOM 2).

P: Era proibido falar em italiano?

E: Sim, era proibido.

P: Ah, então foram perseguidos também.

E: Proibiram também, italiano, era proibido [...]. (MECOM 3).

Em outra narrativa o entrevistado diz que já não se fala mais o italiano. "P: E o senhor se lembra do italiano, ou esqueceu? E: Não... muito pouquinho. A gente perdeu aquele ritmo. Perdeu" (MECOM 4).

Uma das entrevistadas fala sobra a leitura de livros em italiano, os quais teriam vindo da Itália com seus pais ao imigraram para o Brasil. Essa mesma entrevistada ressalta que ela e todos os irmãos aprenderão a ler com o pai, segundo a entrevistada: "E: Nenhum é analfabeto, todos sabem ler e escrever, mas aprenderam com ele. Ele passou para a gente o que sabia. Ele tinha muitos livros, tinha uma gaveta cheia de livros [escritos em italiano]" (MECOM, 11).

Com esse trecho pode-se perceber que logo após a vinda dos imigrantes para a região havia algumas iniciativas do ensino em língua italiana. $\mathrm{O}$ que denota, ao menos no início do período da colonização, a manutenção da língua italiana.

Sobre o ensino escolarizado na localidade ressalta-se a seguinte fala: 
P: E a aula era tudo em português assim? Em brasileiro...

E: Tudo em brasileiro.

P: Não era em italiano?

E: Não, nada. Deus o livre, nem podia abrir a boca em italiano (MECOM 1).

Brito (2006) esclarece que, durante os anos de 1938 e 1939 o governo brasileiro procurou inviabilizar as escolas etnicamente diferenciadas, por meio de algumas medidas tais como, a colocação de nomes brasileiros nas escolas localizadas em regiões coloniais, a direção das escolas deveria ser ocupada por brasileiros natos, o português como língua a ser utilizada, entre outras. Além disso, também houve à inclusão no currículo das disciplinas de história e geografia do Brasil, educação moral e cívica e educação física, ademais deveria ter-se atenção com o uso dos símbolos nacionais e as comemorações das datas pátrias.

Seguindo nessa linha de raciocínio, é possível abordar a Colônia Maciel e a Escola Garibaldi. Primeiramente, é necessário, novamente, pontuar que a Garibaldi sempre foi uma escola pública, o que, de certo modo, pode indicar que estaria alinhada ao que o poder público pensava. Entretanto, algumas problematizações podem ser levantadas a partir da análise do contexto e das fontes consultadas. A primeira delas diz respeito ao próprio nome da escola, "Garibaldi". Por tratar-se de uma colônia formada por italianos foi escolhido para "patrono" da escola, o nome de um mito na historiografia, Giuseppe Garibaldi. Todavia, o nome permanece até os dias atuais, o que pode de certa maneira estar relacionado com a ligação entre comunidade local e escola, visto que o grupo era de descendentes italianos. Ao analisar os relatórios do município de Pelotas percebe-se a seguinte fala: "procurei homenagear nos institutos de ensino figuras insignes da nossa collectividade, designadamente aquellas que se devotaram à nobre missão educativa" (RELATÓRIO DA INTENDÊNCIA, 1928, p. 97). Nessa frase nota-se que o administrador preocupou-se em registrar como eram escolhidos alguns nomes de escolas, homenageando os que haviam contribuído para a educação.

Souza (1998), escrevendo sobre os grupos escolares da Primeira República no Estado de São Paulo, traz que o estado a fim de captar recursos para a instrução designava o nome das escolas aqueles que contribuíssem para as instituições. Como aludido antes, o município de Pelotas também se utilizou dessa prática. Por esse viés, o nome da Escola Garibaldi poderia estar ligado à própria comunidade ter ajudado na construção da instituição e por isso o nome homenageado era um personagem importante italiano. A indagação maior é como, mesmo durante o período de nacionalização, o nome foi mantido. No entanto, é necessário ponderar que Giuseppe Garibaldi é considerado, também, um personagem importante também na história brasileira, "o herói dos dois mundos" e por isso, seu nome na instituição escolar não representava ameaça a campanha de nacionalização (DORNELES, 2012). Além disso, no período republicano alguns personagens da historiografia tiveram suas representações ressignificadas, o que poderia explicar ter sido mantido o nome da instituição.

Outro ponto interessante refere-se à permanência do professor Rodeghiero na instituição, tendo em vista que este era descendente de família italiana. Infere-se que um dos motivos para a sua permanência na escola esteja relacionado com a sua inserção na comunidade.

É necessário trazer para a discussão a legislação municipal: atos, leis e decretos do período do Estado Novo. Seria de especial relevância compreender localmente, como o município esteve envolvido na política educacional da nacionalização do ensino. Porém, é oportuno registrar a dificuldade no que tange a preservação dessa documentação pelo poder público municipal. Não se encontra esse material, o qual enriqueceria o entendimento e a compreensão da especificidade local. Essa não preservação abre espaço, ainda que breve, para a discussão da salvaguarda de documentos que não são mais utilizados cotidianamente, mas configuram-se como importantes fontes para a pesquisa histórica e o ofício do historiador. Encontrou-se uma portaria do ano de 1943 que fornecem alguns elementos que serão tratados posteriormente.

Como a Escola Garibaldi esteve sempre ligada ao poder público, os aspectos da nacionalização estiveram mais presentes desde o início da instituição. Desta forma, na época da nacionalização do ensino, a escola não passou por tantas restrições quanto as escolas étnicas, por exemplo. Entretanto, por estar situada em uma região de imigração, o sentimento de italianidade fez-se presente e ainda se faz presente nos dias atuais. Nesse sentido, algumas considerações são necessárias. O fato do professor José Rodeghiero ser da localidade e do mesmo grupo étnico proporcionou a manutenção da escola e o apoio 
comunitário local, mesmo em uma instituição pública. Outra questão refere-se ao grupo ser resistente às pessoas que não fossem da localidade, como, por exemplo, os professores das escolas anteriores a Garibaldi, os quais a comunidade não se identificava, do mesmo modo que o grupo que se instalou na localidade na década de 1940, para construir a ferrovia no local, também gerou alguns conflitos com a comunidade. A referida ferrovia ligou os municípios de Pelotas a Canguçu (município vizinho a 48 quilômetros). Para a sua construção vieram pessoas externas à Colônia Maciel. Como o período foi grande (aproximadamente 10 anos), instalaram-se na localidade familiares dos trabalhadores. Por conseguinte, as crianças dessas famílias foram estudar na Escola Garibaldi. No início o estabelecimento dessas famílias, na colônia, causou "estranhamento" por parte dos moradores locais, visto que a comunidade da Maciel era relativamente pequena, seus membros conheciam-se, a maioria era oriunda do processo imigratório que ocorreu na localidade. No que diz respeito à instituição escolar, os entrevistados rememoram que as crianças eram mais "atrasadas" em relação aos demais, conforme a entrevista:

Era tudo tão difícil, com aquela turma, crianças do pessoal da ferrovia, eram muito atrasados, entre crianças não dava conflitos, o professor também não dava chance, fazia obedecer, pode ser que tinha tido alguma coisinha, mas não marcou muito, o professor não dava moleza para ninguém e tinha que ser naquele ambiente que tinha ali tinha que ser. É muito diferente (P.P., 2015, depoimento maio de 2016, grifos nossos).

Por esse ângulo, é notável que esse grupo imigrante, constituído inicialmente por italianos majoritariamente, foi em alguns momentos mais "reservado" em relação a outras pessoas que não as do local. Assim sendo, é permissível o questionamento sobre o ensino na escola ter sido somente em português ou não. Um dos indícios convergentes nessa vertente, seria, como trazem os entrevistados, a questão dos alunos provenientes das famílias "de fora" instaladas na Maciel serem, de acordo com essas memórias, mais "atrasados" e com mais dificuldade na aprendizagem. Outra reflexão que se junta a essa é a comunidade não ter se adaptado aos outros professores anteriores.

Nesse sentido, há um aspecto identitário envolvido, o grupo, constituído devido ao processo imigratório, colonizou aquele espaço, assim como se empenhou na construção e/ou cobrança daquelas instituições consideradas necessárias e importantes, como, por exemplo, a Igreja do local e, de certa forma, a escola também esteve imbuída nesse processo. Por esse motivo, talvez se explique a "não abertura" a outros grupos. Decerto que não é possível realizar generalizações, entretanto podem ser empreendidas algumas discussões acerca do pertencimento étnico.

Antes da criação da Escola Garibaldi, em 1928, existira na localidade outras duas escolas. Uma dessas escolas era comunitária, iniciou suas atividades no ano de 1915 e não se sabe exatamente quando fechou e nem a regularidade das aulas. As informações obtidas através da oralidade ${ }^{5}$ assinalam que, nessa escola, os pais dos alunos subsidiavam o salário do professor para ministrar as aulas. Nesse sentido, quando as crianças já estavam alfabetizadas deixavam de frequentá-la, provocando dificuldade de manutenção e regularidade do estabelecimento educativo na localidade. Anterior a essa escola comunitária, existia no local uma escola estadual, a qual foi criada cinco anos antes daquela. Essa escola acabou fechando também por falta de frequência.

No manuscrito produzido por José Rodeghiero é descrito, antes de iniciar a escrever sobre a Escola Garibaldi, a chegada dos imigrantes na localidade e a constituição das escolas acima citadas. No documento encontra-se a seguinte narrativa acerca da escola criada em 1910:

Anos depois da fundação da Colônia foi criada no mesmo local onde se acha a Escola "Garibaldi" uma escola estadual sobre a regência do professor José da Fontoura Grilo, que por alguns anos numa rústica propriedade de pau a pique e barro foi ouvida a sua abalizada voz, mas pouco apreciada por tenderem aquela gente a conservação da língua italiana, a ponto de tentarem tirar o dedicado professor. E por falta de frequência em sua escola foi o referido professor [...]. Ficando por alguns anos a Colônia Maciel sem escola (MANUSCRITO, p. 01, grifo nosso).

Uma informação relevante a ser observada no manuscrito do professor, e que também aparecem na oralidade, é o fato dessas escolas ministrarem o ensino em português, entrando em conflito com os imigrantes de origem italiana, os quais tinham um dialeto próprio e gostariam de manter a conservação da língua italiana. Sendo a escola um ambiente onde o ensino era ministrado na língua portuguesa, havia, além da dificuldade na 
aprendizagem e na alfabetização, uma questão cultural étnica envolvida, a vontade da manutenção da língua italiana.

Nessa perspectiva, podem-se inferir dois pontos: o primeiro é justamente a importância que essa comunidade dava ao ensino e à escola, criando na localidade uma escola particular onde a própria comunidade subsidiava o salário do professor. Em primeiro lugar, não se tinha a obrigatoriedade do ensino. Segundo, o que se pretendia com a educação na escola era aprender a ler, escrever e realizar as primeiras operações matemáticas, noções essas que logo fossem dadas, não havia mais a necessidade de se continuar na escola.

$\mathrm{O}$ segundo ponto diz respeito à incompatibilidade linguística. Enquanto a comunidade prezava a língua materna, a escola traria o ensino na língua pátria, em português, gerando dificuldades, sobretudo, na alfabetização.

Dessa maneira, as escolas anteriores a Garibaldi não tiveram duração prolongada, pelo fato da falta de matrícula. Essa "falta de alunos" pode ser explicada, talvez, pela questão do conflito da língua mencionado acima e, também, pelo fato de que, nesse período, as concepções de educação que se tinham não eram as mesmas dos dias atuais. Sobre o professor que ministrou aula na escola antes da formação da Garibaldi uma das entrevistas reforça:

P: O senhor não sabe por que motivos esse professor não deu certo lá com os italianos?

E: Olha os italianos não eram fáceis, puxa não eram fáceis, eles tinham aquelas manias lá deles, e o professor, seguia um sistema e eles tinham outro, aí não deu certo (MECOM 5).

Nesse ínterim, é notável que havia, por parte da comunidade local, o interesse no ensino ministrado na língua ou no dialeto italiano. Outra narrativa oral rememora que:

E: Não. Já perdemos tudo. Mas, na nossa venda ali na Maciel, ali no Sanetti (...), nós comprávamos coisa que o pai mandava, em italiano. Nós não falávamos brasileiro. Quando nós íamos na escola, nós era, nós era... era, era ganoso [...] para falar só italiano. Depois entramos na escola e aí começou. O pai e a mãe começaram a dar duro, que não era para falar italiano, isso que aquilo, aquele outro, aí parou tudo (MECOM 3).

Dessa forma, uma escola e um professor com o ensino somente na língua portuguesa não correspondiam às expectativas da comunidade. Um dado interessante refere-se ao motivo do fechamento das escolas anteriores a Garibaldi: a falta de frequência. Porém, quando se analisam os relatórios do município de Pelotas encontra-se informação de uma escola com 30 alunos no ano de 1915 na Colônia Maciel, o que denota que havia alunos na localidade para frequentar a escola e mesmo assim essa acaba fechando. Claro que esse é um número presente no relatório e a realidade do número de alunos poderia ser outra. No entanto, observa-se, a partir do livro de atas da Escola Garibaldi que, no início das aulas em 1929, a escola contou com um número significativo de alunos, a saber, 37 alunos, sendo 33 no primeiro ano e 4 no segundo. Com isso pode-se perceber que há alunos frequentando a escola desde o seu início. Isto indica que havia crianças na localidade para frequentar uma escola, bem como havia interesse da comunidade na escolarização de seus filhos. A partir disso, é permissível algumas considerações. As escolas anteriores não terem logrado êxito pode estar relacionado com a identificação com o professor que ministrava as aulas, por questões étnicas, por exemplo, aliado à vontade desse grupo na manutenção da língua italiana, sendo que a escola viria como um meio de nacionalizar.

Nesse ponto, pode-se inferir sobre a possibilidade de a comunidade não querer colocar os alunos na escola, o que pode indicar dois tópicos. $\mathrm{O}$ primeiro, diz respeito à discussão sobre o ensino ser em português ou em italiano, e segundo, relacionado com o primeiro, refere-se à inserção do professor na comunidade, o que pode ser perpassado por questões de identidade, sobretudo étnicas.

A continuidade da Escola Garibaldi sem interrupção deve-se a figura pessoal do professor José Rodeghiero e o fato dele permanecer na instituição liga-se a vinculação do docente na comunidade. Tendo em vista que, além de ser da própria comunidade o grupo identificava-se por questões étnicas e religiosas e o professor participava dos assuntos locais, tais como: o envolvimento do docente com a "Sociedade Cooperativa Vitivinícola", uma associação que tratava da plantação de uvas e fabricação de vinhos, onde o professor tinha as funções de secretário e orador nos momentos necessários.

Em entrevista com os filhos do professor José Rodeghiero, estes trazem a seguinte fala:

E: Então esse colégio era particular, ele tinha muitos alunos que pagavam, aí depois o governo deu uma subvenção para ele, pagava uma parte

Horizontes, v. 36, n. 2, p. 19-35, mai./ago. 2018 
por mês para ele, para ajudar, mas aí depois na Maciel tinha um professor que era brasileiro $e$ não deu certo com os italianos lá. Um dia o povo, não sei talvez já tinha prova escrita naquele.

E: Fala qualquer coisa no histórico.

E: É, eu sei que foram tudo de porrete lá, para dar no professor, então, naquele tempo ainda não era prefeito, era subentendente, foi lá onde o pai lecionava, lá na casa dele, em Campos Lima, em Caneleira e disse: olha tu tens que ir para a Maciel, é o único que pode acertar aqueles italianos, então o pai foi para lá, mas aí depois teve que fazer concurso para se efetivar lá (MECOM, 5, grifos nosso).

Nesse trecho, pode-se notar que os filhos do professor abordam essa questão de que o professor "brasileiro" não deu certo com os italianos e, assim, o professor Rodeghiero foi para a Maciel. É necessário problematizar que essa é uma narrativa dos filhos falando sobre seu pai. À vista disso, compreende-se que havia por parte da comunidade resistências quanto aos professores tidos como "brasileiros".

Dessa forma, fica visível que havia, por parte do grupo local, certa resistência no que se referem às iniciativas escolares anteriores a Garibaldi, principalmente tangenciada por questões étnicas linguísticas.

\section{A nacionalização na Escola Garibaldi}

$\mathrm{Na}$ Escola Garibaldi ao analisar os documentos da escrituração escolar identifica-se uma fiscalização na escola por parte do poder público. No manuscrito, produzido pelo professor, é mencionado sobre os relatórios enviados a Diretoria de Educação, sobretudos os alusivos a Semana da Pátria. Ao analisar os livros de atas de exames finais e de disciplinas escolares percebe-se, também, esse controle e fiscalização. Da mesma forma, ao analisar os índices de aprovação escolar, percebe-se que o maior percentual de reprovação dos alunos nos exames finais é justamente no período do Estado Novo. O que pode indicar um maior controle nesse período e uma exigência maior na alfabetização e, talvez, a questão da língua causou certa dificuldade.

Sobre as disciplinas escolares, ao estudar os livros de disciplinas da Garibaldi, percebe-se que durante o período do Estado Novo as disciplinas de história pátria, geografia e educação moral e cívica foram sempre ministradas.

Esses livros, conforme os relatórios intendenciais, seriam controlados pela administração municipal. Observando as anotações nos livros da Escola Garibaldi percebe-se a fiscalização nos documentos, pois é possível encontrar anotações das pessoas que fiscalizavam esses livros, o que denota vigilância por parte do poder público em relação às escolas.

Algo recorrente na Escola Garibaldi, nesse período, são as visitas por parte da administração municipal e da Diretoria de Educação. O professor registra essas visitas como algo positivo que demonstra, na sua visão, uma preocupação e uma dedicação do poder público com essa escola. Entretanto, essas visitas efetuavam-se, acredita-se, mais como uma forma de fiscalização do ambiente escolar, visto que, nessa época, havia de forma mais acentuada essa inspeção nas instituições escolares.

Nesse período, havia uma série de documentos necessários a serem enviados à Diretoria de Educação. Encontram-se nos registros da Garibaldi menção a essa obrigatoriedade de enviar a documentação exigida, conforme pode ser notado no escrito do professor: "como nos anos anteriores também neste foi enviado Relatório geral a Diretoria de Educação e sistematicamente feito Relatório da Semana da Pátria" (MANUSCRITO, p. $05)$.

Ao entrevistar os alunos do professor Rodeghiero, os quais estudaram na instituição durante a década de 1940, estes rememoram às festividades da Semana da Pátria na localidade, os desfiles realizados durante toda a semana, alguns entrevistados atribuem à figura do professor essa organização. Conforme as narrativas havia desfiles durante toda a semana na frente da Escola Garibaldi, uma entrevistada relembra:

Que eu lembro só tinha a semana da pátria. $\mathrm{Na}$ semana da pátria eram 7 dias marchando na estrada, nós íamos até a ponte da estrada de ferro e voltava marchando, e tinha os guris que tinham os tambores e todos com um "V" de fita verde e amarela no tapa pó. Ele [o professor] era muito ativo para isso [...] (C. M. E., depoimento julho de 2015).

Em relação às festividades da Semana da Pátria pode-se refletir sobre o período em que esses alunos estavam na escola, década de 1940, na qual os princípios da política de Nacionalização do Ensino foram amplamente disseminados, fortalecendo aspectos cívicos e patrióticos. Os entrevistados relembram de uma forma saudosista dos desfiles da Semana da Pátria, como sendo algo 
festivo e bonito e que hoje não há mais na localidade. Neste ínterim, são pertinentes os estudos sobre a memória. Para Candau (2014, p. 33), “[...] a parte da lembrança que é verbalizada (a evocação) não é a totalidade das lembranças [...]". E, como destaca Bosi (1994, p.55), "[...] na maior parte das vezes, lembrar não é reviver, mas refazer, reconstruir, repensar, com imagens e ideias de hoje, as experiências do passado [...] a lembrança é uma imagem construída pelos materiais que estão agora a nossa disposição [...]". Assim, os entrevistados lembram a partir do que significado que os acontecimentos tiveram para si.

Um documento da Diretoria de Educação de Pelotas do ano de 1942, a portaria de número 12, aborda sobre as referidas festividades da Semana da Pátria no município:

Nas festas cívicas, que são os grandes dias santos da Pátria, é obrigatório o comparecimento de todos os professores e alunos, sob a pena de lhe ser contada falta nesse dia, (artigo 224, XV, do decreto Lei 1715, de 28 de outubro de 1938.
Excetuam-se, aqui, os que estiverem legalmente licenciados ou dispensados. O programa dessas festas será mandado a Diretoria com 3 dias de antecedência (PORTARIA $N^{\circ} 12,1942$ ).

A partir dessa citação, pode-se compreender que as festividades da Semana da Pátria eram frequentes no município, além disso, havia a obrigatoriedade da presença dos professores nas comemorações, pois a escola cumpriria um papel importante nas práticas nacionalizadoras. Decerto que esse é um pequeno fragmento para compreender a atuação local na nacionalização do ensino no município de Pelotas. Entretanto, como já mencionado, é escasso o material salvaguardado no que tange a esse aspecto da história do município. Desta forma, foram utilizadas outras tipologias de fontes, como os jornais, entrevistas e fotografias.

Com a realização das entrevistas foram encontradas algumas fotografias, as quais são importantes de serem analisadas neste texto, porque mostram elementos da política nacionalizadora.

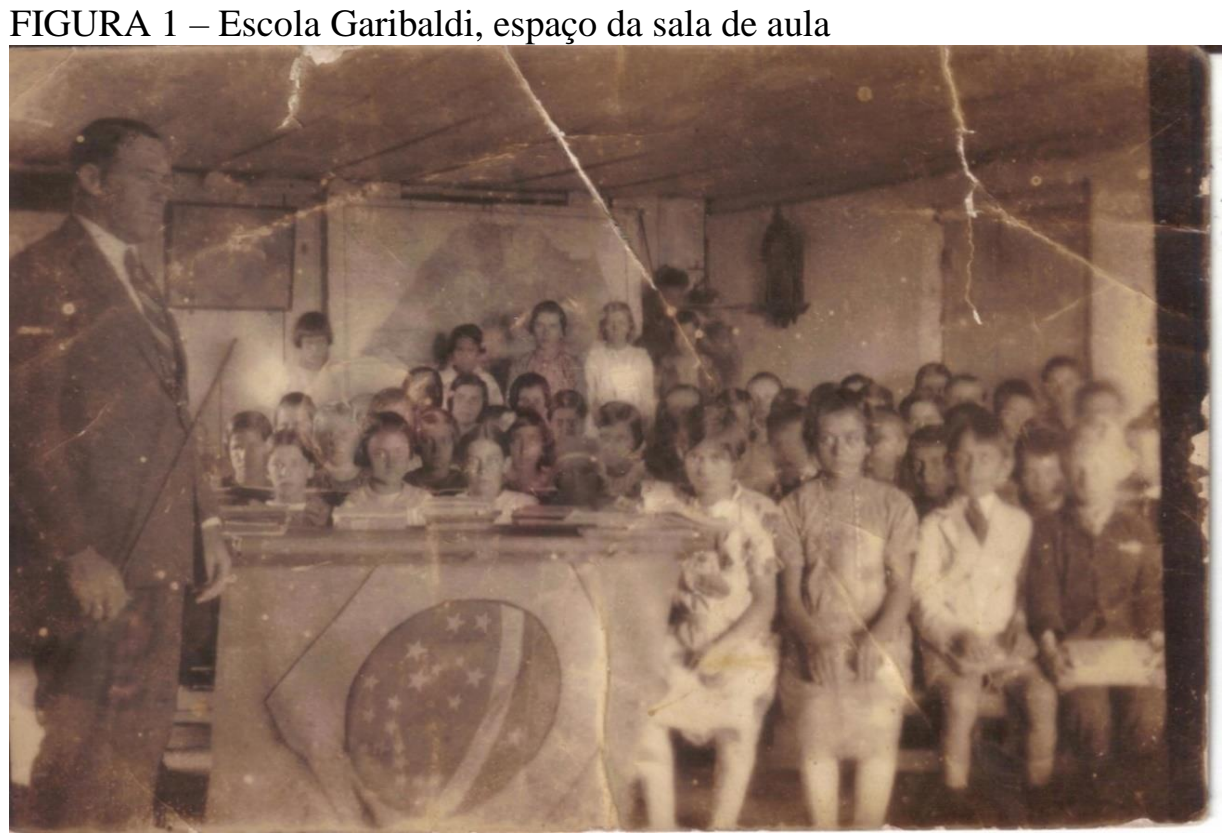

Fonte: Acervo pessoal de Daniel Rodeghiero

Não se tem nenhum indicativo da data desta imagem. Entretanto, compreende-se que a falta dessa informação não prejudica a análise. Pode-se perceber o professor na frente da classe, assim como a sala de aula cheia de alunos, alguns em pé, inclusive. Sobre a quantidade de alunos, pode-se pensar que, sim, poderiam haver muitos alunos estudando no mesmo espaço, o qual não era grande, mas, também, pode ser que, para este momento da foto, estejam reunidos os alunos dos dois turnos em que a escola funcionava, porém esse só existiu a partir de 1945.

No espaço escolar percebe-se a presença de alguns materiais, como, por exemplo, mapas na parede. Em primeiro plano, há a bandeira do Brasil, indicando aspectos da Nacionalização do Ensino. Conforme pontuou-se anteriormente, a Escola Garibaldi não esteve dissociada do contexto das 
políticas para a nacionalização. As duas imagens a seguir indicam que a nacionalização esteve presente na localidade. As fotografias não são no espaço da sala de aula, mas, sim, dos alunos na localidade, uma delas, especificamente, é das comemorações da Semana da Pátria na Colônia Maciel, com a presença dos alunos e comunidade local.

FIGURA 2 - Turma de alunos em passeio na localidade

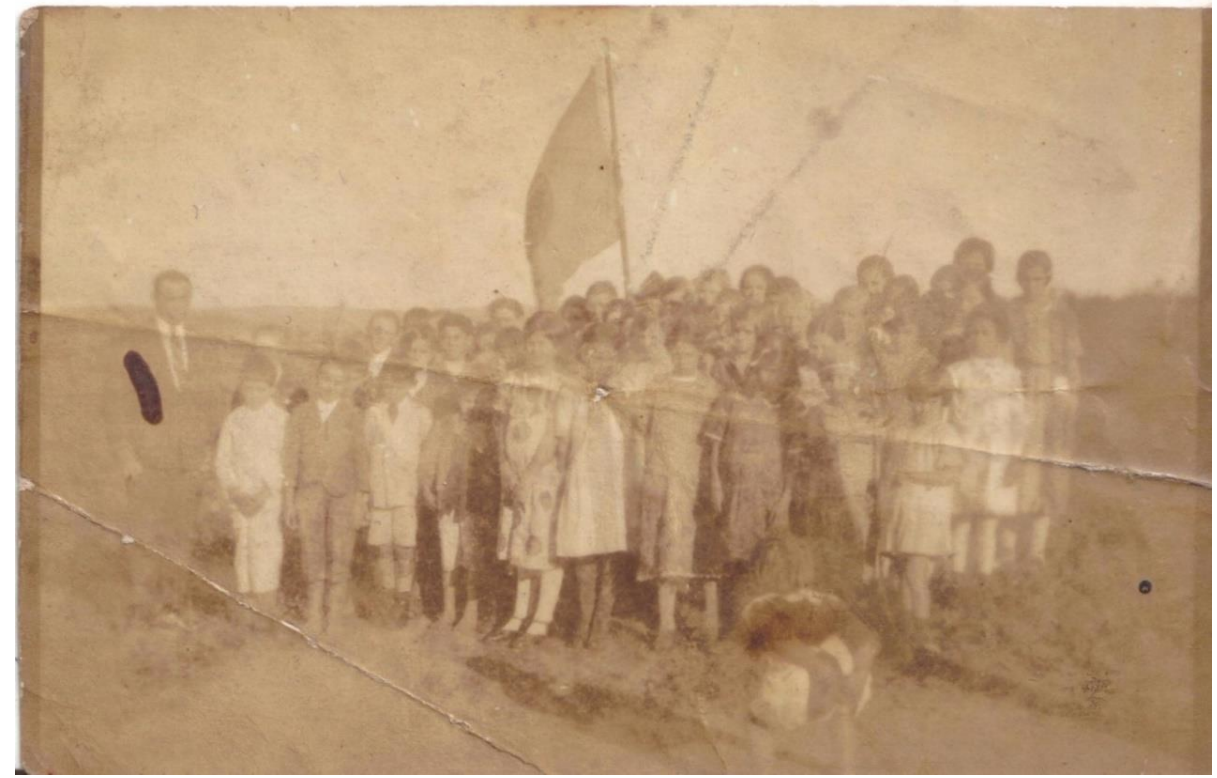

Fonte: Acervo pessoal de Daniel Rodeghiero

$\mathrm{Na}$ imagem acima, pode-se perceber a bandeira do Brasil ao fundo e o professor Rodeghiero com os alunos da Escola Garibaldi. Não é possível identificar na foto qual era o local exato da foto, mas de acordo com os entrevistados da pesquisa, era próximo a escola.

FIGURA 3 - Semana da Pátria na Colônia Maciel, 1942

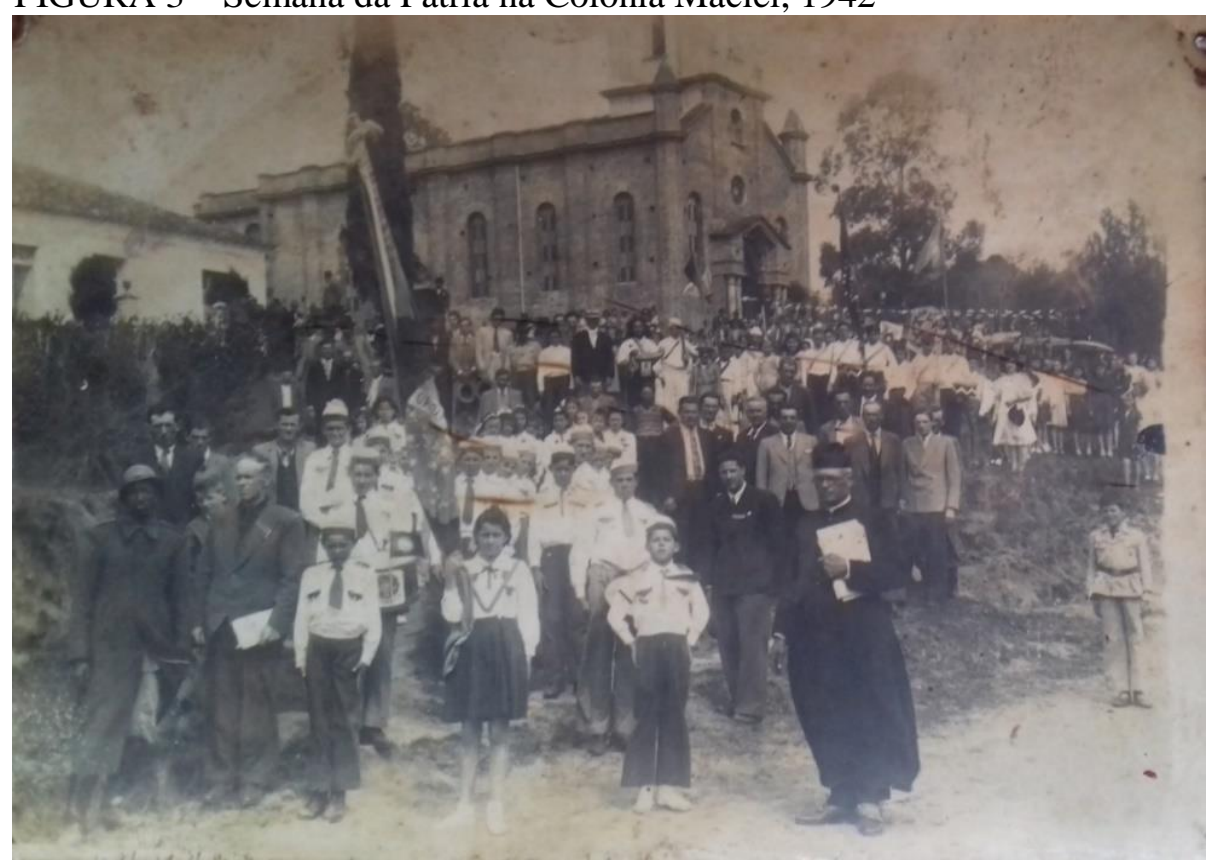

Fonte: Acervo pessoal de Neri Rodeghiero

Nestas imagens, as quais estão fora do

ambiente da sala de aula, percebem-se fortemente os 
elementos da nacionalização. A figura 3 mostra as comemorações da Semana da Pátria (segundo um dos entrevistados, presente na foto, refere-se ao ano de 1942). Na localidade, nota-se o uso de uniformes para este momento, sendo que nas demais imagens os alunos não utilizam uniformes no cotidiano escolar, o que demonstra a importância dessas festividades. Ainda, na imagem, percebe-se a presença do Padre da igreja local, bem como da comunidade. À frente, está o professor Rodeghiero e o Padre Jacob Lorenzet, juntamente com três alunos, os filhos do professor e, após os demais alunos, no fundo o prédio da igreja de Sant'Ana. Em uma foto posada, a presença da bandeira do Brasil torna-se explicável por serem as comemorações da Semana da Pátria. Neste momento, ressalta-se o envolvimento também da Igreja e da comunidade nas festividades, o que denota que era um momento importante na localidade. Os entrevistados da pesquisa observam que havia desfiles durante toda a semana na frente da Escola Garibaldi.

A partir do exposto acima, pode-se perceber a partir das fontes mobilizadas como se deu no espaço geográfico da Colônia Maciel as políticas para a nacionalização do ensino. A Escola Garibaldi mesmo sendo uma instituição pública, por estar situada em uma área de imigração fazia-se sentir os efeitos da nacionalização.

\section{Considerações finais}

Com o propósito de discutir e analisar a nacionalização do ensino na Escola Garibaldi e na Colônia Maciel é construído esse texto. O qual teve por objetivo delinear, a partir das fontes analisadas, alguns pontos para a discussão, ainda que persistam algumas indagações.

Dessa forma, a guisa de conclusões sistematiza-se o exposto até aqui. Um item diz respeito à restrição do uso da língua italiana durante o período do Estado Novo e da Segunda Guerra Mundial. O que denota a vontade do grupo na preservação do uso do idioma. Assim como, as outras duas escolas anteriores a Garibaldi terem fechado, mesmo tendo crianças na localidade evidencia questões de pertencimento étnico envolvidos. Nesse sentido, reforçam-se as questões étnicas identitárias, podendo ser demonstrativo de que o grupo teria interesse na manutenção de seus costumes, bem como no ambiente escolar a não adaptação com professores de fora. As escolas anteriores foram fechadas com o motivo da falta de frequência, porém, conforme se procurou demostrar acima, o fechamento foi mais ocasionado pela falta de identidade da comunidade com os professores do que com não ter crianças na localidade. Quando, então, o professor Rodeghiero assume a recémcriada escola pública na Colônia Maciel há uma regularidade no que tange a continuidade do ensino.

Outro item merecedor de destaque é a resistência que o grupo local tinha com outras pessoas externas à localidade, tais como os trabalhadores da estrada de ferro, havia conflitos tanto em um contexto mais geral quanto na instituição educativa. A rememoração dos entrevistados sobre esse período é evocada sempre a partir da tensão entre os dois grupos.

Como se pode observar, por meio das fontes mobilizadas, é notável que houve na Escola Garibaldi um controle e uma fiscalização nesse período do Estado Novo nos documentos da escrituração escolar. O professor era encarregado de enviar para os órgãos competentes a documentação exigida e, da mesma forma, eram realizadas celebrações durante as datas cívicas, tais como a Semana da Pátria.

Com isso, fica compreensível que as políticas nacionalizadoras fizeram-se presentes na localidade da Colônia Maciel, assim como na Escola Garibaldi. Decerto que a instituição escolar não foi atingida pela Nacionalização do Ensino da mesma forma que, por exemplo, as escolas étnicas, até mesmo por ser uma escola situada dentro da esfera pública de ensino, entretanto fez-se presente controle e fiscalização.

Por fim, é necessário mencionar que só houve nacionalização para aqueles que, de acordo com o pensamento da época, precisavam ser nacionalizados. Se não houvesse resistências e/ou interesse na manutenção de alguns dos hábitos culturais e da própria língua falada não haveria necessidade de nacionalizar esse grupo imigrante. De acordo com o apresentado, o grupo foi resistente a algumas situações, podendo estar relacionada com a vontade de manutenção de seus hábitos ou sua língua materna, o que mostra a necessidade de nacionalizar esse grupo por meio de medidas nem sempre tão coercitivas e agressivas quanto para outros grupos imigrantes, como, por exemplo, a etnia alemã. Porém, fez-se presente na localidade, a restrição ao uso do idioma, na instituição escolar, os desfiles cívicos, as disciplinas escolares ministradas, bem como o controle na fiscalização desses documentos, indicando que a instituição escolar não estava dissociada do contexto da época. 


\section{Notas}

1 Para mais detalhes de como foi realizada essa organização do material ver Castro (2017).

2 Esse era o jornal da situação.

3 Essas entrevistas que são acervos foram utilizadas da maneira que estavam transcritas, porém optouse por referir o pesquisador pela letra $\mathrm{P}$ e $\mathrm{o}$ entrevistado pela letra $\mathrm{E}$.

4 Nas entrevistas do banco de imagens e sons do MECOM optou-se por não identificar os sujeitos entrevistados e sim nomeá-los com a sigla "MECOM" seguidos da numeração.

5 Entrevistas com moradores locais e com os profissionais que atuam na escola.

\section{Referências}

ALMEIDA, Dóris Bittencourt; GRAZZIOTIN, Luciane Sgarbi S. Memórias de escola em colônias agrícolas judaicas no Rio Grande do Sul: narrativas orais do acervo do Instituto Cultural Marc Chagall (1904-1930). Revista Cadernos de História da Educação, v.15, n.3, p. 1031-1054, 2016.

BENCOSTTA, Marcus Levy. Memória e cultura escolar: a imagem fotográfica no estudo da escola primária de Curitiba. História, v. 30, n. 1, p. 397411, 2011. Disponível em: <http://www.scielo.br/pdf/his/v30n1/v30n1a19.pdf> . Acesso em: 11 jun. 2015.

BOSI, Ecléa. Memória e sociedade: lembranças de velhos. 3. ed. São Paulo: TA, 1994.

BRITO, Silvia Helena Andrade de. A Educação no Projeto Nacionalista do Primeiro Governo Vargas (1930-1945). In: LOMBARDI, I. C.; SAVIANI, D.; NASCIMENTO, M. I. M. (orgs.) Navegando pela história da Educação. Campinas, SP: Graf. FE: HISTEDBR, 2006. Disponível em: $<$ http://www.histedbr.fe.unicamp.br/navegando/periodo _era_vargas.html>. Acesso em: 20 de março de 2016.

BURKE, Peter. A testemunha ocular: história e imagem. Inserir edição. Bauru: Edusc, 2004.

O que é história cultural? Inserir edição. Rio de Janeiro: Jorge Zahar Editor, 2005.

CANDAU, Joel. Memória e Identidade. 1.ed. 1. reimpressão. São Paulo: Contexto, 2014.

CASTRO, Renata Brião de. A Escola Garibaldi e o professor José Rodeghiero na Colônia Maciel Pelotas (RS) (1928 - 1950): grupo local e etnia. 2017. 220 f. Dissertação (Mestrado em Educação) Programa de Pós-Graduação em Educação, Universidade Federal de Pelotas, 2017.

CERQUEIRA, Fabio Vergara. Serra dos Tapes: mosaico de tradições étnicas e paisagens culturais. In: MICHELON, Francisca Ferreira; FERREIRA, Maria Letícia Mazzuchi (orgs.). Seminário internacional de memória e patrimônio: memória, patrimônio e tradição, 4, 2010. Anais... Pelotas: Editora e Gráfica Universitária da UFPel, 2010, p. 872.

CERTEAU, Michel de. A escrita da história. Inserir edição. Rio de Janeiro: Forense Universitária, 1982.

CORSETTI et al. A política educacional no Rio Grande do Sul e a questão da Nacionalização do Ensino (1930/1945). História da Educação, n. 23, p. 173-192, 2007.

DIÁRIO POPULAR. Edições de 1928 a 1950. Bibliotheca Pública Pelotense, Pelotas/RS.

DORNELES, Laura de Leão. Risorgimento e Revolução: Luigi Rossetti e as ideias de Giuseppe Mazzino no Movimento Farroupilha. $1^{\mathrm{a}} \mathrm{ed}$. Porto Alegre: EDIPUCRS, 2012

FERREIRA, Marieta de Moraes; AMADO Janaína. Apresentação. In: FERREIRA, Marieta de Moraes; AMADO, Janaína (orgs.) Usos e abusos da História Oral. 8.ed. Rio de Janeiro: FGV Editora, 2006.

GIL, Natália de Lacerda. HAWAT, Joseane El. O tempo, a idade e a permanência na escola: um estudo a partir dos livros de matrícula (Rio Grande do Sul, 1895-1919). Revista História da Educação, Porto Alegre, v. 19, n 46, p. 19 - 40, 2015.

HALBWACHS Maurice. A memória coletiva. Inserir edição. São Paulo: Centauro Editora, 2003.

HILSDORF, Maria Lucia Spedo. História da educação brasileira: leituras. $1^{\mathrm{a}} \mathrm{ed}$. Cengage Learning Editores, 2003.

LE GOFF. História e Memória. Inserir edição. 
Campinas: Editora da UNICAMP, 1990.

LUCA, Tania Regina. História dos, nos e por meio dos periódicos. In: PINSKY, Carla. Bassanezi. (org.). Fontes Históricas. 3. ed. São Paulo: Contexto, 2015, p. 111-153.

LUCHESE, Terciane Ângela. Abrasileirar os coloninhos: histórias e memórias escolares na região colonial italiana do Rio Grande do Sul (1937-1945). In: QUADROS, Claudemir de (org.) Uma gota amarga: itinerários da nacionalização do ensino no Brasil. Santa Maria, RS: editora ufsm, 2014, p. 191-232.

MANUSCRITO. Histórico da Escola Garibaldi escrito por José Rodeghiero. Inserir data. MAUAD, Ana Maria. Através da imagem: fotografia e história interfaces. Revista Tempo, vol. 1, ${ }^{\circ} .2$, p. 73 - 98, 1996. Disponível em: < xa.yimg.com/kq/groups/20486128/.../name/Mauad+ Fotografia+e+Hist\%2B'ria.pdf $>$. Acesso em: 15 de mar. 2016.

MAUAD, Ana Maria; LOPES, Marcos Felipe de Brum. Imagem, história e ciência. Boletim do Museu Paraense Emílio Goeldi. Ciências Humanas, v. 9, n. 2, p. 283-286, 2014. Disponível em: <http://www.scielo.br/pdf/bgoeldi/v9n2/a02v9n2.pd f>. Acesso em: 15 de mar. 2016.

MECOM. Banco de imagens e sons do Museu Etnográfico da Colônia Maciel, 2006.

MEIHY, José Carlos Sebe Bom; HOLANDA, Fabíola. História oral: como fazer, como pensar. 2.ed. São Paulo: Editora Contexto, 2014.

NORA, Pierre. Entre memória e história: a problemática dos lugares. Projeto História: Revista do Programa de Estudos Pós-Graduados de História, v. 10, p. 7 - 28,1993.

OLIVEIRA, Maria Augusta Martiarena. A educação durante o governo de Augusto Simões Lopes (19241928). 2005. 242 f. Dissertação (Mestrado em Educação) - Programa de Pós-Graduação em Educação, Universidade Federal de Pelotas, Pelotas, 2005.

RELATÓRIO DA INTENDÊNCIA. Apresentado ao Conselho Municipal em 20 de setembro de 1928 pelo Intendente Augusto Simões Lopes, Off. Typ. Do "diário popular", 1928.

SAVIANI, Dermeval. História das ideias pedagógicas no Brasil. Inserir edição. Campinas: Autores Associados, 2007.

SCHWARTZMAN, Simon; BOMENY, Helena Maria Bousquet; COSTA, Vanda Maria Ribeiro. Tempos de Capanema. 1. ed. Rio de Janeiro: Paz e Terra, 1984.

SEYFERTH, Giralda. Os imigrantes e a campanha de nacionalização do Estado Novo. Repensando o estado novo. Rio de Janeiro: FGV, p. 199-228, 1999.

SOUZA, Rosa Fátima de. Templos de civilização: a implantação da escola primária graduada no Estado de São Paulo, 1890-1910. 1. ed. São Paulo: Unesp, 1998.

TAMBARA, Elomar; QUADROS, Claudemir; BASTOS, Maria Helena C. Educação (1930-1980). In: GERTZ, René (dir.). República: da revolução de 1930 à ditadura militar (1930-1985). Passo Fundo: Méritos, 2007. V. 4, p. 315-333.

WEIDUSCHADT, Patrícia. A nacionalização do ensino no contexto imigratório. Encontro da associação sul rio grandense de pesquisadores em história da educação, 15, 2009, Caxias do Sul. Anais... Caxias do Sul: ASPHE, 2009, p. 1 - 15.

WEIDUSCHADT, Patrícia; FISCHER, Beatriz T. Daudt. História oral e memória: aportes teóricometodológicos na investigação de trajetórias docentes. In: FERREIRA, Márcia Ondina Vieira; FISCHER, Beatriz. T. Daudt; PERES, Lúcia. Maria Vaz. (orgs). Memórias docentes: abordagens teóricometodológicas e experiências de investigação. São Leopoldo: Oikós, 2009, p. 66 - 84.

XAVIER, Libânia Nacif. O debate em torno da nacionalização do ensino na Era Vargas. Educação (UFSM), Santa Maria, v. 30, n. 2, p. 105-120, 2005.

ZICMAN, Renée Barata. História através da imprensa: algumas considerações metodológicas. Revista do Programa de Estudos Pós-Graduados de História. v. 4, p. 89 - 102, 1985. 


\section{Sobre as autoras}

Renata Brião de Castro: Doutoranda no Programa de Pós-graduação em Educação da Universidade Federal de Pelotas (UFPEL). Mestre em Educação pela mesma instituição. Bacharel em Museologia (UFPEL). Membro do grupo de pesquisa, Centro de Estudos e Investigações em História da Educação (UFPEL). Bolsista CAPES.

Patrícia Weiduschadt: Professora efetiva do Departamento de Fundamentos de Educação da Faculdade de Educação e membro permanente do Programa de Pós-graduação em Educação da Linha de pesquisa Filosofia e História da Educação, da Universidade Federal de Pelotas (UFPEL). Doutora em Educação pela Universidade do Vale do Rio dos Sinos - Unisinos.

Submetido em abril de 2017.

Aprovado em dezembro de 2017. 